\title{
PENGARUH SPORTS MASSAGE PADA EKSTREMITAS BAWAH TERHADAP FLEKSIBILITAS PEMAIN SEPAK BOLA
}

\author{
Oleh: \\ Nurkholis Ipang Ripai dan Ali Satya Graha \\ Jurusan Pendididkan Kesehatan dan Rekreasi FIK UNY
}

\begin{abstract}
Abstrak
Tujuan penelitian ini adalah untuk mengetahui pengaruh sports massage pada ekstremitas bawah setelah latihan terhadap fleksibilitas. Penelitian ini merupakan penelitian quasi experimental design yang mempunyai kelompok kontrol, namun tidak dipilih secara random (nonequivalent control group design). Populasi penelitian adalah pemain tim sepak bola di Desa Argomulyo Cangkringan Sleman Yogyakarta sebanyak 20 orang dengan sampel berjumlah 10 orang. Analisis data yang digunakan dalam penelitian ini adalah uji hipotesis dilakukan dengan uji analysis of varians (Anova). Hasil penelitian menunjukkan bahwa terdapat hasil signifikan terhadap pengaruh sports massage pada fleksibilitas
\end{abstract}

Kata kunci: sports massage, ekstremitas bawah, fleksibilitas, dan sepak bola

Pada saat berolahraga, terjadi perubahan besar dalam sistem sirkulasi dan pernapasan, bahwa keduanya berlangsung bersamaan sebagai bagian dari respons homeostatik. Berolahraga terjadi dua kejadian yaitu peningkatan curah jantung dan redistribusi darah dari otot-otot yang tidak aktif ke otot-otot yang aktif. Sepak bola merupakan salah satu olahraga yang diminati oleh sebagian besar warga Indonesia, baik di kota maupun pedesaan olahraga ini sangat populer. Olahraga sepak bola memiliki ciri khas yaitu berjalan, jogging, running, sprint secara intermiten (Wong \& Hong, 2005: 473). Cedera yang paling sering dialami pemain sepak bola adalah cedera bagian ekstremitas bawah (75-85\%), mayoritas mengenai ankle, hamstring dan lutut (Von Beijsterveldt A. M., 2013: 21). Cedera traumatis umum termasuk memar (contusions), muscle strains (biasanya memengaruhi hamstring, paha depan atau otot adductor) dan ligament sprains (ankle dan sendi lutut) (Chaterje S, 2014: 25).

Beberapa manfaat fleksibilitas otot di antaranya meningkatkan kebugaran fisik, peningkatan kemampuan untuk belajar dan mampu melakukan gerakan keterampilan, meningkatkan relaksasi, pengembangan kesadaran tubuh, megurangi nyeri otot, menurunkan kekakuan, meningkatkan ketahanan terhadap cedera jaringan (ligamen, tendon, otot) (Janine, 2010: 4). Cara yang dapat membantu dalam meningkatkan fleksibilitas selain dengan metode latihan yaitu berupa manipulasi massage dengan penerapannya dapat menurunkan ketegangan antagonis otot nonaktif (Mostafaloo, 2011: 17). 


\section{Sports Massage}

Penggunaan sports massasge dipilih karena dirasa manfaat sports massage yang tepat dalam manipulasi untuk menurunkan denyut nadi, frekuensi pernapasan, dan meningkatan fleksibilitas. Manfaat Sports massage yaitu mencegah otot kram dan kejang, meningkatkan fleksibilitas dan mengendurkan otot-otot yang tegang, mencegah cedera, memfasilitasi pemulihan yang cepat setelah aktivitas berat (Donkin, 2009: 9). Priyonoadi (2011: 5-6) menyatakan sport massage terutama diberikan kepada olahragawan, serta macam dan cara memijatnya lebih berpengaruh terhadap kelancaran peredaran darah, merangsang persyarafan, meningkatkan kekenyalan otot (elastisitas), mengurangi atau menghilangkan ketegangan saraf, dan mengurangi rasa sakit. Sports massage adalah pemijatan, pengurutan dan sebagainya pada bagian-bagian tertentu dengan tangan atau alat-alat khusus untuk melancarkan peredaran darah sebagai cara pengobatan atau untuk menghilangkan rasa lelah (Fitriyah N., Wismanadi dan Siantoror, 2016: 136).

\section{Anatomi Ekstremitas Bawah}

Pada kerangka anggota badan bawah pada umumnya dapat dibedakan menjadi dua, yaitu tulang-tulang panggul gelang panggul (ossa cinguli extremitas inferior) dan tulang-tulang anggota bawah yang bebas (ossa extremitas inferior librae) (Sudibjo, 2011: 41).

\section{Otot Extremitas Bawah}

Otot adalah sebuah jaringan konektif yang tugas utamanya adalah berkontraksi yang berfungsi untuk menggerakkan bagian-bagian tubuh baik yang disadari maupun yang tidak (Wiarto, 2014: 27). Dalam tubuh manusia otot dibedakan menjadi tiga, yaitu otot lurik, otot polos dan otot jantung (Suharjana, 2013: 29). Otot lurik atau fibra otot serat lintang adalah yang terbanyak di tubuh manusia dibandingkan dengan fibra otot yang lain (Sudibdjo dkk, 2011: 19). Kurang lebih tubuh manusia 40\% terdiri atas otot rangka (otot lurik), sementara otot polos dan otot jantung berjumlah hampir $1 \%$ (Suharjana, 2013: 29). Pembahasan mengenai otot rangka bagian bawah tubuh akan dijelaskan lebih detailnya pada pembahasan berikut dengan cara membagi per bagian tubuh ektremitas bawah dan otot yang melekatnya. Otot paha depan atau sering disebut dengan kelompok otot quadriceps terdiri atas empat bagian, yaitu rectus femoris, vastus medialis, vastus lateralis dan vastus intermedius (Chavan dan Wabale, 2016: 112).

Otot paha bagian belakang memiliki tiga otot utama, yaitu biceps femoris, semitendinous dan semimembranous merupakan kelompok otot hamstring (Johnston, 2014: 1). Istilah "hamstring" mengacu pada tiga otot yang terletak di paha bagian belakang, di antaranya semitendinosus (ST) dan semimembranosus (SM) yang terletak di sisi medial, dan biceps femoris di sisi lateral. Berikut tentang struktur otot hamstring: Otot-otot tungkai bagian bawah depan terdiri dari, musculus tibialis anterior, musculus ekstensor digitorum, musculus pereneus tertius, musculus extensor hallucis longus, 
musculus perenous longus dan musculus perenous brevis. Kemudian bagian belakang terdiri dari musculus gastrocnemius, musculus soleus, musculus plantaris (Sudibjo dkk, 2011: 92).

\section{Fleksibilitas}

Fleksibilitas adalah berbagai gerakan yang memainkan peranan penting yang berhubungan dengan kesehatan dan komponen kebugaran fisik, kegiatan sehari-hari termasuk aktivitas olahraga. Fleksibilitas merupakan kemampuan suatu jaringan atau otot untuk memanjang semaksimal mungkin sehingga tubuh dapat bergerak dengan lingkup gerak sendi yang penuh, tanpa disertai rasa nyeri (Wismanto, 2011: 78). Fleksibilitas atau kelentukan adalah kemampuan gerakan tubuh dalam suatu gerak sendi dengan melibatkan elastisitas (kelenturan) otot, tendon, dan ligamen (Suharjana, 2013: 109). Fleksibilitas adalah kemampuan otot untuk memperpanjang dan memungkinkan sendi atau sendi yang lain berdasarkan rentang gerak sendi (ROM) maksimal.

\section{METODE PENELITIAN}

Penelitian ini merupakan penelitian quasi experimental design yang mempunyai kelompok kontrol, namun tidak dipilih secara random (nonequivalent control group design) Hal pertama yang dilakukan peneliti adalah melakukan pretest. Setelah dilakukan pretest kemudian peneliti membagi kelompok menjadi dua, yaitu kelompok eksperimen dan kelompok kontrol. Kelompok eksperimen diberi perlakuan (X1) sports massage dan kelompok kontrol tidak diberi perlakuan.

Penelitian ini dilaksanakan di lapangan Kridomulyo Argomulyo, Cangkringan, Sleman, Yogyakarta. Waktu penelitian dilaksanakan pada tanggal 9 April 2017 selama satu hari. Populasi dalam penelitian ini adalah pemain sepak bola yang ada di tim ACSY Soccer Club di Desa Argomulyo, Cangkringan, Sleman, Yogyakarta dengan jumlah populasi sebesar 20 subjek. Sampel dalam penelitian ini berjumlah 10 sampel. Penentuan pengelompokan sampel dilakukan secara ordinal pairing. Dengan kriteria sampel peneitian ini yaitu, jenis kelamin laki-laki, usia di atas 18 tahun dan masih aktif mengikuti latihan di tim sepak bola ACSY SC di Desa Argomulyo, Cangkingan, Sleman, Yogyakarta. Pembagian kelompok dilakukan dengan cara mengurutkan hasil pretest dari yang tertinggi sampai dengan terendah.

\section{HASIL PENELITIAN DAN PEMBAHASAN}

Pengaruh sport massage pada ekstremitas bawah setelah latihan terhadap fleksibilitas pemain sepak bola di Desa Argomulyo, Kecamatan Cangkringan, Sleman, Daerah Istimewa Yogyakarta. Berdasarkan hasil penelitian uji anova antara pretest dan posttest 1 maupun posttest 2 pada kelompok eksperimen fleksibilitas ditemukan perbedaan dengan hasil signifikan. Data posttest 1 dengan pretest sebesar 0,004, posttest 2 dengan pretest sebesar 0,006 dan posttest 2 dengan posttest 1 sebesar 0,000. Data tesebut disebut signifikan karena hasil menunjukkan kurang dari 0,05 (signifikan $<0,05$ ). Dengan 
demikian bahwa perlakuan sports massage setelah latihan memberikan peningkatan terhadap fleksibilitas otot yang signifikan.

Data juga menyebutkan adayanya perubahan fleksibilitas posttest 1 dengan pretest pada batas bawah sebesar $-3,864 \mathrm{~cm}$ dan batas atas sebesar $0,364 \mathrm{~cm}$. Data frekuensi pernpasan posttest 2 dengan pretest hasil menujukan pada batas bawah sebesar $-0,592 \mathrm{~cm}$ dan batas atas sebesar 3,692 $\mathrm{cm}$. Selanjutnya data frekuensi pernapasan posttest dengan posttest 1 hasil menunjukkan pada batas bawah sebesar $2,788 \mathrm{~cm}$ dan batas atas sebesar $3,811 \mathrm{~cm}$.

Hal ini sesuai dengan teori yang menyebut manfaat sports massage yaitu mencegah otot kram dan kejang, meningkatkan fleksibilitas dan mengendurkan otot-otot yang tegang, mencegah cedera, memfasilitasi pemulihan yang cepat setelah aktivitas berat (Donkin, 2009: 9). Menurut Priyonoadi (2011: 5-6) sport massage terutama diberikan kepada olahragawan, serta macam dan cara memijatnya lebih berpengaruh terhadap kelancaran peredaran darah, merangsang persyarafan, meningkatkan kekenyalan otot (elastisitas), mengurangi atau menghilangkan ketegangan saraf dan mengurangi rasa sakit.

\section{KESIMPULAN}

Ada pengaruh signifikan perlakuan manipulasi sports massage pada ekstremitas bawah setelah latihan terhadap fleksibilitas pemain sepak bola di Desa Argomulyo, Cangkringan, Sleman, Yogyakarta. Berdasarkan kesimpulan penelitian di atas, ada beberapa saran yang dapat disampaikan yaitu bagi pemain sepak bola ACSY SC Argomulyo khususnya dan tim sepak bola lain pada umumnya agar menggunakan sports massage untuk membantu pemulihan setelah latihan. Pelatih atau therapist tim sepak bola agar meningkatkan kreativitas metode massage untuk membantu proses pemulihan pemain setelah latihan sehingga kelelahan otot akibat aktivitas fisik segera teratasi dan dapat membantu dalam peningkatan fleksibilitas otot.

\section{DAFTAR PUSTAKA}

Chaterjee S., Neepa B., Satabdi B., et al. (2014). Sports Injury With Special Reference To Soccer: Causes, Consequences and Prevention Strategies. America Journal of Sports Science, 2(6-1), 24-30.

Chavan, S. K. And Wabale, R. N. (2016). Reviewing Morpology Of Quadriceps Femoris Muscle. Pravara Institute Of Medical Sciences, 33, 2, 112-117.

Donkin Scott. (2009). The Extraordinary Benefits ff Daily Massage. Lincoln: All Rights Reserverd.

Fowler Janine. (2010). Everybody Stretch: A Physical Activity Workbook for People With Multiple Sclerosis. Canada: Greenwood Tamand, Inc.

Johnstone Arlene. (2014). Hamstring Muscle: When It Comes To The Hamstring Do Not Get Hamstring. ACSM. Hlm. 1-8. 
Mostafaloo. (2011). The Effect of One Session Massage In the Lower Limb Muscle on Flexibility, Power and Agility Test Perfomance In Soccer Players. Journal of Jahrom University of medical Science, 10, 2, 16-21.

Sugiyono. (2013). Metode Penelitian Pendidikan. Bandung: Alfabeta.

Suharjana. (2013). Kebugaran jasmani. Jogja; Global media Yogyakarta.

Von Beijsterveldt, A.M. (2013). Injury Prevention For Adult Male Soccer Players. The Netherlands, Ipskamp Drunkkers, Enschede.

Wiarto, Giri. (2013). Fisiologi dan Olahraga. Yogyakarta: Graha Ilmu.

Wismanto. (2011). Pelatihan Merode Active Isolated Stretching Lebih Efektif Daripada Contract Relax Stretching Dalam Meningkatkan Fleksibilitas Otot Hamstring. Jurnal Fisioterapi. Vol. 11. No. 1. Hlm. 77-95.

Wong \& Hong. (2016). Soccer Injury In The Lower Extremities. Sports Med, 39, 473-482.

Yuni Fitriyah N., Himawan W. \& Gigih S. (2016). Pengaruh Sports Massage Dan Terapi Bekam Terhadap Penurunan Kadar Asam Laktat Dan Denyut Nadi. Journal Of Physical Education, Health And Sports. Hlm: 135-143. 